\title{
The influence of trust and attitudes on the purchase frequency of organic produce
} Jerome Dumortier, Keith S. Evans, Carola Grebitus \& Pamela A. Martin

\begin{abstract}
Growth in organic food sales is mainly due to consumers becoming more aware of health issues and environmental concerns. Understanding the drivers of organic consumption is crucial to predict future market outcomes. In this analysis, we expand previous research by including general and institutional trust variables in addition to consumer attitudes to examine organic food purchases. Food production is unobservable and hence, consumers need to exhibit trust with respect to organic production and certification. A bivariate ordered probit model applied to U.S. survey data confirms that organic purchases are determined by health, nutrition, and taste. In some cases, general trust and trust in media are statistically significant. Trust in institutions that are involved in the organic certification process is not statistically significant. A hierarchical cluster analysis grouping consumers based on trust and attitudes shows that (dis)trust in the organic certification and supply chain does not hinder organic food market growth.
\end{abstract}

\section{Keywords}

Organic food, trust, cluster analysis, bivariate ordered probit

\section{Introduction}

According to the U.S. Department of Agriculture (USDA), organic food demand has increased by double-digits for most years since 1990 (USDA ERS, 2016). In 2013, U.S. organic food sales reached $\$ 35.1$ billion representing close to $5 \%$ of all U.S. food sales and projections suggest that demand will continue to grow at 14\% annually until 2018 (Daniells, 2014; Mosier \& Thilmany, 2016). Growth in organic sales has also been resilient to the 2008 economic downturn, growing faster than all other food sectors (Nie and Zepeda, 2011; Osteen et al., 2012). Certified organic cropland in the U.S. increased from 163,250 to 1,248,000 hectares between 1992 and 2011 (ERS, 2013). Given the past and expected future growth in the industry, the U.S. has devoted significant resources toward organic food production. The Agricultural Act of 2014 (also known as the 2014 Farm Bill) increases funding to organic research compared to the 2008 Farm Bill, especially to improve the economic data available on the organic sector (USDA ERS, 2015). Also, the bill more than doubled the funding to organic farmers to ease the financial burden of 
required USDA organic certification. This increase in subsidies for the certification process is expected to increase production to meet the growing demand for organic produce. Better information about the underlying drivers of organic food production is important for policy makers interested in the efficacy of past efforts (e.g., organic certification) and directing new resources toward areas that will promote a sustainable industry.

Concepts of organic farming were developed in German and English speaking countries about a century ago (Schösler, de Boer, \& Boersema, 2013). Establishment of organic agriculture was driven by producers (e.g., interest in soil conservation) as well as consumers who were interested in the promotion of "pure food," involved in the environmental movement, or distrustful of agricultural and industrial production methods (Mosier \& Thilmany, 2016). To reduce the distrust, an important step in the supply chain is the certification and labeling as "organic" that signals to the consumer that organic practices were employed in the production process. While several of the characteristics such as color and odor are directly observable to the buyer, the actual farming practice used to produce the food and the benefits from consuming organic versus conventional food are not observed. The asymmetry of information between the buyer and seller may be sufficient, in certain settings, to preclude the sale (Yiridoe, BontiAnkomah \& Martin, 2005). Thus, uncertainty and trust are hypothesized to be important factors in the decision to purchase organic produce.

The USDA organic certification process and label is an effort to reduce this asymmetry and establish trust. The USDA employs the national "USDA organic" label to screen products for consumers. According to the USDA, organic agriculture is "a set of cultural, biological, and mechanical practices that support the cycling of on-farm resources, promote ecological balance, and conserve biodiversity. These include maintaining or enhancing soil and water quality; conserving wetlands, woodlands, and wildlife; and avoiding use of synthetic fertilizers, sewage sludge, irradiation, and genetic engineering" (USDA, 2015). The USDA defines organic food standards with third-party entities providing the certification based on those standards. Given this participation level by the USDA, accounting for consumers' trust in the certification process and labeling of organic food may be of interest to U.S. policy makers and food supply chain actors concerned with influencing organic purchase behavior. Trust in the institutions providing information, and in the entities that set and enforce organic standards, could be an important factor in the organic purchase decision, especially in light of the price premium associated with 
organic food. The influence of institutional trust has not yet been explored for organic food purchases and this analysis aims to fill this research gap.

In this study, we separate trust into two categories: general trust toward others and trust in the institution which in turn shape consumers' attitudes over time through information about organic food. General trust is captured in the General Social Survey (GSS) question regarding the trustworthiness of people in general. In addition to general trust, institutional trust or trust in sources of information, e.g., government, farmers, and media, has been identified as important in the food safety literature (de Jonge et al., 2008b). We hypothesize that trust in the standard setting and certifying institutions as well as trust in general positively affect the purchase frequency of organic produce.

Against this background, we conducted a survey of U.S. households in fall of 2012 and collected information about their purchase behavior for organic strawberries and tomatoes, their trust and attitudes toward organic food, and socio-demographics. We focus on strawberries and tomatoes as they are examples of organic produce that comprise the largest share of U.S. organic sales, and are consumed frequently in the U.S. (Dimitri and Greene, 2002). Using the data obtained from the survey, we estimate the joint purchase frequency decision using a bivariate ordered probit model. Lastly, we use cluster analysis to segment organic consumers by trust and attitudes toward organic in order to provide recommendations for efficient and effective marketing strategies and policies. Segmenting consumers provides information to food marketers and policy makers about appropriate targeted communication strategies for specific groups of organic shoppers (Nandi et al., 2016).

Vukaspvič (2016) points out that the future organic market will be mostly driven by the demand side. Thus, it is important to understand what motivates and what hinders consumers to purchase and consume organic food. This paper extends the literature by exploring the influence of attitudes surrounding the unobservable attributes of organic food, and trust in the institutions providing information about these attributes, as it relates to the purchase frequency of two commonly sold organic produces in the United States. We find that age, income, and private benefits are important in determining the purchase frequency of organic food. Results with respect to institutional and general trust are mixed although consumers' preferences about who certifies organic largely matches the current practices in the United States. In addition, the cluster analysis reveals how market segments will respond differently to marketing strategies. Finally, 
this study offers guidance for future research to develop methodologically sound approaches to linking trust, attitudes, and purchasing behavior.

\section{Literature Review}

The growth in demand for organic products is mainly due to consumers becoming increasingly interested in health and nutrition as well as environmental issues (Vukaspvič, 2016; Nandi et al. 2016). For example, attributes such as health, nutritional value, and taste have been identified as common drivers in organic food purchases (Zanoli and Naspetti, 2002; Hughner et al., 2007; Gracia and de Magistris, 2008; Whitmarsh \& O’Neill, 2010; Grebitus et al., 2011a). Gil, Gracia $\&$ Sanchez (2000) find that organic consumers are concerned about the nutritional value, health, and food quality of conventional food. Nandi et al. (2016) refer to this as the "push-pull" theory of factors that push consumers away from conventional food and pull them towards organic food. Motives to purchase organic food and products can generally be categorized into private and social benefits. Private benefits are those directly enjoyed by the consumer such as the health aspects of non-organic foods (e.g., no pesticides), taste, and nutrition (Becker et al., 2016). Social benefits are received by the public such as reduced pesticide exposure, increased animal welfare, or reduced nitrogen runoff. Mosier and Thilmany (2016) cite worries about food safety and environmental aspects as motivations to purchase organic food. Rousseau and Vranken (2013) note that consumers are additionally influenced by their beliefs about environmental consequences of organic food production as well as social and personal norms. Income is often identified as a strong determinant (Smith et al., 2009), while other variables such as age, education, number of children, and household size have provided mixed results (Gracia and de Magistris, 2008; Grebitus et al., 2011b; Yue et al., 2010). Price has also been identified as contributing to the purchase of organic food for consumers in the U.S. (Smith et al., 2009; Thompson, 1998), the Netherlands (Verhoef, 2005), and Southern Italy (Gracia and de Magistris, 2008). Aertsens et al. (2009) provide a comprehensive review of the factors influencing organic demand and consumption.

Previous research found that positive attitudes towards organic food are a predictor of its consumption (Thøgersen, 2002; Saba \& Messina 2003, Aertsens, 2009). Thøgersen (2002) found that beliefs about the consequences of consuming organic food influences the attitudes held towards organic food. Because of the nature of unobservable characteristics, consumers must 
evaluate organic products based on personal evaluations, i.e., attitudes, before making a purchase decision. Attitudes may influence purchasing behavior in important ways, affecting psychological processes such as perception, learning, and thinking (Ajzen, 1991; Agarwal \& Malhotra, 2005). This is intriguing as the attitudes about organic food may not be supported by scientific studies. For example, recent research finds no statistical evidence of differences in nutrient content of organic and conventional food (Forman and Silverstein, 2012; SmithSpangler et al., 2012). This suggests that changing attitudes may be the greatest challenge when attempting to alter the food choices of individuals, e.g., from buying conventional to buying organic (Asp, 1999). Understanding the influence of attitudes related to organic production is fundamental in predicting and affecting food choices. To this end, we separate attitudes about organic food into three dimensions, i.e., attitudes about (1) the private benefits of consuming organic food, (2) organic farming practices, and (3) the image of organic food, to identify their impact on purchase frequency. Altruistic factors such as concerns for the environment have been identified as being positively related to organic food purchases but with less of an influence than egoistic drivers (Gil et al., 2000; Magnusson et al., 2003).

Trust, as an explanatory variable, is potentially important for the consumption of food in general and organic food in particular as trust is related to attitudes and risk. In the presence of unobservable attributes, consumers face the risk of making an unsatisfying purchase or being exposed to food safety issues (Lobb et al., 2007; de Jonge et al., 2008a). Recent consumer studies incorporate trust as an important factor that influences beliefs, attitudes, and purchasing decisions (Allen et al., 2008; Walter and Schmidt, 2008; Schumacher, 2010; Steiner and Yag, 2010; Ding et al., 2012). Previous literature suggests that trust is a function of credible information, e.g., signals of quality or safety. Consumers having trust in the information presented are willing to accept a higher price for the product since the information reduces asymmetric information (Barber, 1983; Roosen et al., 2015). McCluskey (2000) demonstrates that third-party certifiers are necessary in the organic food market to ensure that producers do not falsely claim organic production practices. As such, organic labeling and the USDA organic certification can be interpreted as communicating information to consumers about organic food thereby affecting attitudes and trust (Johnson and Slovic, 1994). In this paper, we measure trust along two dimensions: (1) general trust and (2) institutional trust. General trust is believed to rest on moral values or world views and can be considered to be relatively stable over time (Glaeser 
et al., 2000; Uslaner, 2002, 2008). Uslaner (2008) describes general trust as "a value that rests on an optimistic view of the world and one's ability to control it." Institutional trust is based on experience, built over time, and considered fragile (Yamagishi and Yamagishi, 1994; Mansbridge, 1999).

Finally, we employ a cluster analysis that aims to identify consumers based on trust and attitudes to be used for targeted marketing strategies. The cluster analysis will also provide an internal validation of our analysis. Saba and Messina (2003) segmented consumers of organic fruits and vegetables according to similar characteristics of consumers and found that some consumers have less positive attitude about organics and perceived the use of pesticides as less of a problem. Nandi et al. (2009) found that over 50\% of their respondents can be categorized as food lovers but there are also almost $21 \%$ that are "food indifferent."

\section{Methods}

The frequency at which an individual purchases organic produce depends on their preferences for those products. While we are interested in this study of the impact of attitudes towards organic food and trust in information sources on preferences, preferences may also be linked with socio-demographic characteristics, such as income, age, and gender. We model an individuals' preferences affecting their purchase frequency of organic produce using the random utility framework (McFadden, 1974). Let

$$
v_{i, k}=f\left(X_{i, k} ; \beta_{k}\right)+\epsilon_{i, k} \text { for } i=1, \ldots, N \text { and } k=1,2
$$

denote the indirect utility of individual $i$ consuming organic food $k(k=1$ denotes organic strawberries and $k=2$ organic tomatoes) where $X_{i, k}$ contains the individual characteristics observable to the researcher (e.g., age and income). In this model, we assume that higher values of $v_{i, k}$ correspond to stronger preferences for organic food $k$ and therefore that individual $i$ will purchase this food more frequently. ${ }^{1}$ The function $f(\cdot)$ captures the relationship between observable individual characteristics and indirect utility. In the following, we assume that $f(\cdot)$ takes on a linear form, i.e., $f\left(X_{i, k} ; \beta_{k}\right)=\beta_{k} X_{i, k}$, where $\beta_{k}$ captures the marginal influence of observable characteristics on preferences for organic food $k$. Finally, $\epsilon_{i, k}$ is an idiosyncratic error term capturing information unobservable to the researcher. Indirect utility is a continuous

\footnotetext{
${ }^{1}$ Since both strawberries and tomatoes are perishable we can assume that a high purchase frequency is related to high consumption.
} 
variable that is unobservable to the researcher. Instead, we observe the stated frequency decision $y_{i, k}$ of survey respondents which fall within $J$ discrete purchase frequency categories. Individuals with higher indirect utility purchase the good more frequently and provide a higher response in the survey. Let $\mu_{k}$ denote the set of thresholds that divide the unobservable indirect utility of respondents into the observable discrete purchase frequency categories for organic food $\mathrm{k}$, where $\mu_{0, k}<\ldots<\mu_{J, k}$. Then respondent $i$ 's stated frequency decision can be written as,

$$
y_{i, k}=\left\{\begin{array}{c}
J \text { if } \mu_{J-1, k}<v_{i, k} \leq \mu_{J, k} \\
\vdots \\
2 \text { if } \mu_{1, k}<v_{i, k} \leq \mu_{2, k} \\
1 \text { if } \mu_{0, k}<v_{i, k} \leq \mu_{1, k}
\end{array}\right.
$$

The cutoff points $\mu_{\mathrm{j}, \mathrm{k}}$ are unknown and must be estimated. To ensure identification of the model parameters, we fix $\mu_{0, k}=-\infty, \mu_{J, k}=\infty$, and set the intercept to zero.

The bivariate ordered probit provides an efficient econometric framework to recover the model parameters (Greene and Hensher, 2010). This estimator has the added benefit of containing the classic ordered probit as a special case. Using a bivariate standard normal cumulative density function, maximum likelihood provides estimates of the $\beta_{k}$ parameters, cut points $\mu_{k}$, and $\rho_{12}$, the correlation between the error terms between organic strawberries and organic tomato choices. If the error terms are uncorrelated $\left(\rho_{12}=0\right)$, then the decisions to consume organic strawberries and organic tomatoes are independent and the classic ordered probit regression falls out of the log likelihood expression.

In addition to the bivariate ordered probit and to provide an internal validation of our approach, we group the observations in consumer segments using hierarchical cluster analysis (e.g., Hair 2009). Cluster analysis allows us to segment consumers into different target groups based on their attitudes and trust towards organic food in such a way that the degree of association is maximized within a group and minimized with respect to other groups. We employ a hierarchical clustering on the respective variables, using Ward's linkage and a squaredEuclidean distance, to separate respondents into groups. 


\section{Data}

The data source used in this exploratory study is an online survey of U.S. households conducted in September 2012. The sample consists of 186 U.S. private households that were randomly selected by the professional survey provider Qualtrics from a pool of respondents across the contiguous United States. Properly designed and implemented online surveys are equivalent to random digit dial telephone methods with respect to measurement error, collection time and cost (Chang \& Krosnick, 2009; Yeager et al., 2010). The survey focuses on a household's purchase frequencies of organic strawberries and tomatoes, general trust, institutional trust, attitudes toward organic food, and socio-demographics. Of the original 186 respondents, ten were removed from the data set as they were not responsible for food shopping in their household. A description of the sample and explanatory variables included in the regression is provided in Table 1. The sample under-represents households in the 18-24 age bracket and over-represents those in the 25-34 age bracket. This pattern is also illustrated in the apparent over-sampling of households with higher education levels, as those in the 18-24 age bracket are less likely to have finished advanced degrees. In the regression analysis, we control for demographics (e.g., age, income, gender, etc.) to take into account the differences of our sample compared to the U.S. population and to increase the generalizability of our results. Participants chose their income range out of 17 bins and responses were evaluated at the midpoint of each bin and treated as continuous in the regression. Finally, we use a dummy variable to control for college education; equal to 1 if the respondent has a bachelor degree or higher and 0 otherwise.

\subsection{Organic Produce Purchase Patterns}

Purchase patterns of organic produce are of primary importance in this paper. To elicit this information, households were asked to select the frequency of purchase of these goods that best fits their "usual" purchase pattern. Respondents were provided with nine frequency options; these included "Never," "Less than once a year," "Every six months," "Once a month," "Every two weeks," "1-2 times a week," “3-4 times a week," "5-6 times a week," and "Daily." After examining the raw data, we created the category "Almost Daily" by combining the categories of "3-4 times a week," "5-6 times a week," and "Daily." In addition, the categories "Every six month" and "Less than once a year" were grouped into "Rarely." The other categories remained unchanged. Combining responses in this way provided more usable data about the frequent and 
infrequent consumers of the goods. A possible limitation of this study is that the dependent variable account for purchase frequency but not the quantity. While there has been discussion in the literature regarding the researcher's choice of purchase versus consumption frequency, durable goods and bulk purchases introduce a discrepancy between the two measures (Corrigan et al., 2009), our products are perishable and have a short shelf-life thereby minimizing the discrepancy. Hence, we can assume that a high purchase frequency is related to high consumption.

Table 2 displays the cross-tabulated purchase frequencies of organic strawberries and tomatoes. Organic strawberries were purchased by $63 \%$ of the sample while organic tomatoes were purchased by $59 \%$ of the respondents, which is higher than previous studies (Nie and Zepeda, 2011). To examine the joint nature of the consumption outcomes in our data, we calculate the polychoric correlation coefficient $\rho$ for the purchase of the two products. The polychoric correlation coefficient is a statistic for measuring the correlation between ordinal variables that possess an underlying continuous latent variable. We find a strong positive polychoric correlation of $\rho=0.88$ between the stated purchase frequency of organic strawberries and organic tomatoes. Estimation of the bivariate ordered probit provides an estimate for the correlation between errors. This estimate can be interpreted as the polychoric coefficient for the consumption of organic strawberries and organic tomatoes conditioned on observable characteristics.

\subsection{Trust}

One testable hypothesis of this paper is whether trust affects the purchase frequency of organic food. To this end, we separate trust into two sources, (1) general trust toward others and (2) trust in institutions that provide information regarding organic food. To measure general trust, we follow the approach of Glaeser et al. (2000) and use the General Social Survey (GSS) question regarding trust. Households were asked, "Generally speaking, would you say that most people can be trusted or that you should be very careful in dealing with people?" Respondents were given three options: "Most people can be trusted", "You should be very careful in dealing with people", and "I don't know". Only six respondents chose the last answer and 30.9\% answered 
that most people can be trusted. This is consistent with the GSS which indicates a "yes" to this answer by $32.4 \%$ among the U.S. population. ${ }^{2}$

A potentially important source of institutional trust is represented by confidence in the institutions labeling and providing information about organic food. The current organic certification system in the U.S. is based on standards set by the USDA with certification conducted by USDA accredited third-party certifiers (Dimitri and Greene, 2002). To evaluate the confidence in the current system, we asked households to indicate which of six institutions listed should be responsible for organic food certification (multiple answers possible). Farmer groups had by far the most support from $67.6 \%$ of the respondents followed by third-party certifiers (53.4\%), government (47.2\%), non-profit organizations (46.0\%), manufacturing companies $(45.5 \%)$, and retailers $(39.2 \%)$. It is interesting to note that a system not currently used, i.e., certification by farmers, is supported by two-thirds of the respondents--well ahead of the system that is actually used. Previous research has found that food assurance/certification can itself be a source of distrust and thus, to ensure the integrity of the organic system can be problematic (Eden et al., 2008 a,b).

Closely related to the choice on certifying institutions is trust with respect to sources of information regarding food labeled as organic. To assess this, households were asked to evaluate the trustworthiness (on a Likert scale ranging from 1 being "not at all trustworthy" to 5 being "extremely trustworthy") of twelve institutions for information regarding food labeled as organic (Table 3).

To maintain parsimony in our estimator, factor scores were generated from an exploratory factor analysis. To see if a factor analysis is warranted, we calculate Cronbach's alpha, which measures how closely related a set of items are as a group. Values close to 1 indicate evidence that the items measure some latent construct. For the trust variables listed in Table 3, we find $\alpha_{\text {trust }}=0.83$, indicating that there may be underlying latent variables. Factor analysis allows us to identify the underlying latent structure and reduce the institutional trust attribute space from a larger number of more or less highly correlated variables into a few unrelated, independent factors. We use principle-component factors with varimax as the rotational strategy. All factors with an Eigenvalue below 1 are dropped. We use the KaiserMeyer-Olkin (KMO) criterion to test the adequacy of using the factor loadings to generate

\footnotetext{
${ }^{2}$ General Social Survey Data 2012: http://gss.norc.org/documents/stata/2012_stata.zip, accessed 15 March 2016
} 
factors describing institutional trust. Kaiser (1974) suggests that KMO values in excess of 0.7 and 0.8 are middling and meritorious, respectively. Table 3 summarizes the factor loadings that produced four groupings of items with a KMO value of 0.76 . Note that the items in each factor are intuitively related such as "newspapers, magazine, books," "internet," and "TV, radio" for the item "Media."

\subsection{Attitudes}

To gather data regarding consumers' attitudes toward organic food, we ask households to state how strongly they agree (on a Likert scale ranging from $1=$ "Strongly Disagree" to $5=$ "Strongly Agree") to a series of statements about organic produce compared to conventional produce. These statements (which may be true or false) were separated into two main groupings: statements regarding the private benefits of consuming organic food and statements regarding knowledge organic farming practices (as illustrated in Tables 4 and 5). Cronbach's alphas of 0.88 and 0.74 suggest underlying latent variables connecting the responses within each grouping of statements. To explore these latent variables, we conducted separate factor analyses on these groupings. In both cases, we use principle-component factors with varimax rotational strategies. A minimum Eigenvalue of 1 was used to determine the number of factors. The factor loadings in Tables 4 and 5 were used to label factors and create factor scores.

Table 4 contains the statements regarding the private benefits of consuming organic food. Factor analysis on the sample responses to these statements generated a single factor. We labeled this factor "Private Benefits" as it captures the respondent's attitudes that consuming organic food, relative to its conventional counterpart, generates benefits that are private to the consumer, i.e. it is safer, healthier, more nutritious, and tastes better. Positive factor scores are interpreted as stronger than sample mean attitudes about these benefits.

Table 5 lists the statements used in the survey to evaluate consumer's knowledge and perceptions about organic farming practices. Using the exploratory factor analysis, two factors emerge. We label the first factor "Organic Practices" as it captures whether the respondent's attitudes are aligned with actual organic farming practices. The second factor, labeled "Organic Image", emphasizes the statements that are often associated with the ideal image of organic food and production, e.g. the pastoral image, but may or may not be true. For example, while organic 
food is not "only grown by small family-owned farms", it is unclear whether organic food carry less "disease-causing micro-organism" than conventional. ${ }^{3}$

\section{Analysis}

Three versions of the bivariate ordered probit model are estimated to test the joint significance of institutional and general trust (Tables 6 and 7). Likelihood ratio tests suggest that Model 3 (the complete model) provides a statistically better fit of the data than Model $1(p=0.05)$ and Model $2(p=0.08)$. As such, the discussion that follows focuses on the results from Model 3. Estimated coefficients do not reflect marginal effects due to the nonlinear form of the bivariate ordered probit. Therefore, we discuss marginal effects separately from the coefficient estimates (Table 8).

For organic strawberries, we find age, income, attitudes about the private benefits of consuming organic food, and trust in information about organic food from media sources statistically significant. Similarly, we find age, income, and private benefits statistically significant in the organic tomatoes equation. However, rather than trust in media, we find that general trust is a statistically significant factor in the decision to purchase organic tomatoes. Eden et al. (2008a) find that consumers across different socio-demographics display a general level of distrust when it comes to food production and that food labels such as the "USDA Organic" might itself be a source of distrust. Finally, the parameter estimate on the correlation between the error terms of the two equations is both large and statistically significant at the $1 \%$ level. This suggest rejection of independent estimation of the equations.

Table 8 shows the predicted probabilities for the six purchase frequency categories evaluated at the sample means of the data. The average respondent has a $39.6 \%(34.7 \%)$ probability of never consuming organic strawberries (organic tomatoes). The remaining probability is spread across the other five purchase frequency categories, with most of the weight ( $27.3 \%$ for organic strawberries and $25.0 \%$ for organic tomatoes) being assigned to the category "Rarely."

\footnotetext{
${ }^{3}$ Howard (2009) analyzes the consolidation and acquisition of the organic farming sector by corporations and "these transactions are often hidden from consumers through stealth ownership" which contradicts the image of small family-owned farms.
} 
The interesting question is how these probabilities change as we change the explanatory variables, i.e., the marginal effects. For the ordered probit, marginal effects must sum to zero across the categories (Table 8). Therefore, an increase in the probability of an individual choosing one category must be offset by a decrease in the probability of choosing at least one of the other categories. As expected, higher levels of income is associated with a higher probability of purchase organic produce while older respondents are less likely to purchase organic. A $\$ 10,000$ increase in income increases the probability of the average respondent purchase organic strawberries (organic tomatoes) by 2.0 (2.9) percentage points. It is interesting to note that the "never" category exhibits the strongest marginal effect with respect to a change in income. Working in the opposite direction, a one year increase in the age of the average increases the probability of never purchase organic strawberries (organic tomatoes) by $0.7(0.6)$ percentage points. While the marginal effect of income is expected, the marginal effect on age deserves some comment. One explanation for this result is that younger people are more concerned with the health issues associated with the exposure to perceived pesticides present on conventional food. An alternate explanation is that younger households are also more likely to have children present. If these households are concerned with the perceived health risks to their children, their purchase patterns may reflect this.

We are primarily interested in the influence of trust and attitudes about organic food on the purchase frequency of organic produce. Parameter estimates (and marginal effects) on the variables Private Benefits, Organic Practices, and Organic Image allow us to gain insight into how knowledge of organic farming practices and different dimensions of these attitudes affect the purchase frequency decision. Attitudes surrounding the private benefits from consuming organic food are a strong determinant of the frequency decision; statistically significant at the 1\% level. A one unit increase (equivalent to one standard deviation in the sample) raises the probability of purchase of organic strawberries (organic tomatoes) by 13.6 (14.4) percentage points. This confirms previous findings on the motivation of consumers to buy organic (Hughner et al., 2007). This result suggests that efforts to enhance the attitudes in the relative private benefits of organic over conventional food will lead to an increase in the purchase frequency of organic tomatoes and strawberries.

We find no evidence that knowledge of organic farming practices or the organic image significantly affect decision making, Notably, however, the majority of the respondents correctly 
identified organic practices. Less than $10 \%$ disagreed with the statements that there were no manufactured fertilizers or pesticides. And, nearly $60 \%$ of the respondents correctly identifying that organic produce was grown with no manufactured fertilizers and pesticides and had less organic residues (Table 5). There was more ambiguity among respondents about whether organic produce was only grown on small farms, but a majority of respondents correctly disagreed with this question. Our survey results suggests that consumers are generally knowledgeable about organic practices.

Insight is also gained through an examination of the parameter estimates and marginal effect of the general and institutional trust variables. Both general and institutional trust affect the purchase decision, but in very different ways. The average household that is trusting of people in general is more likely to purchase organic tomatoes, and to do so more frequently than its distrusting counterpart. General trust increases the probability of purchasing organic tomatoes by 14.8 percentage points, with 4.3 and 6.1 of this increase in the most frequent purchasing categories ("1-2 times a week" and "Almost daily"). Interestingly, a similar effect is not found for organic strawberries.

Instead, trust in information about organic food provided by media sources affects the probability of purchase organic strawberries. Households that are more trusting of information from media sources about organic food are more likely to purchase organic strawberries. A one unit increase in this index (equivalent to one standard deviation in the sample) produces a 7.5 percentage point increase in the probability of purchase. This is an encouraging result for companies that produce organic strawberries as it suggests that organic marketing is highly effective on a subgroup of the population $(55.7 \%$ of the sample exceed the average level of trust in media sources). A similar effect is not found for organic tomatoes.

We find no evidence in the sample that trust in the institutions providing information about the unobservable characteristics of organic food has an effect on the purchase frequency of organic strawberries and tomatoes. We compare consumers of organic strawberries and organic tomatoes with consumers of conventional products and consumers who buy neither strawberries nor tomatoes. Consumers seem to have sympathy for organic products (including free-range meat); as a result, their choices are largely determined by their responses to the conventional alternatives (de Boer et al., 2009). Those who have the opinion that the conventional products 
should be rejected from their choice set or that the organic product is the best option in their choice set will buy the organic product.

\section{Market Segmentation of Consumers}

Cluster analysis is applied to group consumers into segments that can be used for target-oriented marketing and communication activities. In addition, this analysis provides an internal validation for the regression results from the previous section. Our sample size for the cluster analysis is sufficient since a minimum sample size of 100 is considered necessary to perform segmentation (Hair, 2009). Respondents are clustered into different groups based on their attitudes about organic food (captured in the variables Organic Practice, Organic Image, and Private Benefits), their trust in sources of information (the variables Media, Peers, Ind/Gov, and 3rd), and their response to the general trust question. Table 9 displays the mean characteristics of the four clusters. A dissimilarity measure of 150 provides a natural breaking of groupings from the dendrogram, leaving a four-cluster solution.

Using the mean information contained in table 9, we label the four clusters. In Cluster 1 $(\mathrm{n}=42)$, called the "General Skeptics" group, we observe the lowest level of general trust as well as low trust in information about organic food from peers, industry and government, and third parties. The participants in Cluster $2(\mathrm{n}=61)$, the "Organic Skeptics" group, neither believe that organic produce has fewer pesticides or manufactured fertilizer nor do they believe that organic food generates more private benefits than conventional food. This is consistent with the findings of Saba \& Messina (2003) who identify a consumer group not regarding the use of pesticides as a problem. In Cluster $3(n=40)$, the "Organic Believers" group, the respondents have the strongest positive attitudes surrounding both the image and private benefits associated with consuming organic food. Finally, Cluster $4(n=33)$, the "Informed" group, contains the participants whose attitudes are most closely aligned with actual farming practices but do not believe in the organic image.

To explore how these four groups differ in consumption patterns of organic strawberries and tomatoes, and socio-demographics, we conduct a univariate analysis of variance (ANOVA) and a multivariate analysis of variance (MANOVA). ANOVA is a statistical test of differences in means by analysis of group variances. MANOVA is the multivariate counterpart to ANOVA, testing for heterogeneity of a vector of means. A simple evaluation of p-values provide 
probabilistic statements regarding the statistical significance of differences in mean values across groups. The ANOVA and MANOVA results are shown in Table 10.

Our analyses show that the four groups differ in their consumption of organic strawberries $(p<0.01)$ and organic tomatoes $(p<0.01)$. The four groups also vary in age $(p=$ 0.09), whether children are present in the household $(\mathrm{p}=0.05)$, and whether the participant lives in an urban area $(\mathrm{p}=0.08)$. Mean differences in other socio-demographics are not statistically significant. The MANOVA results show that the four groups differ in their joint purchase of organic strawberries and tomatoes $(\mathrm{p}<0.01)$, and also differ in the participants' overall sociodemographics $(\mathrm{p}=0.02)$.

The purchase frequency observed in the clustered groups is consistent with the marginal effects discussed in Section 5, providing a simple consistency check of the results. For example, the Organic Believers group purchases significantly more organic strawberries and tomatoes than the three other groups. The average respondent in this group is young with lower than average income and a slightly below average general trust. These participants also possess the highest level of trust in media sources for information regarding organic food and have the strongest attitudes in the private benefits of consuming organic over conventional food. Based on the parameter estimates, the probability of the average respondent in the Organic Believers group never purchase organic strawberries (organic tomatoes) is $15.8 \%(16.8 \%)$ below the sample average, while the probability that this participant is a high frequency purchaser (in the top two frequency categories) is $10.5 \%(15.4 \%)$ above the sample average. Therefore, relative to the sample average, participants in this group are more likely to be frequent purchasers of organic strawberries and tomatoes and receptive to marketing efforts, which is consistent with the mean values in table 9.

On the opposite end of the spectrum, the Organic Skeptics group purchase the fewest organic strawberries and tomatoes. The average participant in this group is wealthier and is slightly older than the sample average. This respondent is also the least trusting of information about organic food from the media and do not believe in the private benefits of consuming organic food. Again, based on the parameter estimates we can calculate the probability of this participant being a low and high frequency purchaser of organic strawberries and tomatoes. In this case, we find that the probability of the average respondent in this group never purchase organic strawberries (organic tomatoes) is $8.2 \%(6.5 \%)$ above the sample average, while the 
probability that they are a frequent purchaser is $3.5 \%(3.5 \%)$ below the sample average. Therefore, relative to the sample average, respondents in the Organic Skeptics groups are less likely to purchase organic.

\section{Conclusion}

The organic food sector in the U.S. is growing at a faster rate than any other food related sector and has also been resilient to the economic downturn of 2008. Previous research has analyzed the motivations of consumers to purchase organic. This article extends this literature by including general and institutional trust in the analysis, in addition to attitudes towards organic food. Our exploratory study of the purchase frequency patterns of organic strawberry and tomato consumers, using survey data of U.S. households, provides useful information to organic producers, policy makers, and food supply chain actors.

The results of the bivariate ordered probit and cluster analyses have important marketing implications. First, age and income are important socio- demographics. Younger and wealthier households are more likely to purchase organic food. Marketing strategies may be more effective in targeting these audiences.

Second, because of the unobservable characteristics of organic food, e.g., the actual production practice used and the relative health benefits of consuming organic, consumer beliefs affect the purchase frequency decision. While we do not find evidence in the sample that organic farming practices or the organic image are relevant, the perception of private benefits from consuming organic rather than conventional food is found to be a strong determinant of this decision. This suggests that marketing strategies focusing on the perceived private benefits from consuming organic food are more effective in altering the food choices of individuals, i.e., from buying conventional to buying organic, compared to strategies that focus on educating shoppers regarding organic farming practices.

Third, we find no evidence that trust in the institution involved in the certification process, i.e., third-parties and government, is important to the purchase frequency decision. This is in contrast to recent research suggested that trust may be an important factor in influencing beliefs, attitudes, and purchase decisions, and that external certifiers are necessary in the market for organic food to reduce fraud (McCluskey, 2000; Schumacher, 2010; Steiner and Yag, 2010; Ding et al., 2012). Our findings may be related to the current labeling and certification process in 
the United States. There is a single national organic label in the U.S. and only third party certifiers contracted by USDA are certifying the products. Markets with more than one label, such as in Germany, may lead to different outcomes.

Fourth, the results suggest that general trust and trust in media as a source of information about organic food can be strong influencers of the purchase behavior of organic produce. Marketing through media is effective on a subpopulation of the sample (55.7\% of the sample exceed the average level of trust in media sources).

The cluster analysis reveals that consumer segments will respond differently to marketing strategies. For example, the Organic Believers group is more receptive towards information about organic food from the media than the other three groups. However, they also have the strongest beliefs about the private benefits of consuming organic food, leaving less room for further growth. Therefore, efforts to affect purchase frequency through attitudes may be less effective. Alternatively, the General Skeptics group is responsive to information from media but does not believe in the private benefits of organic. Marketing strategies designed to target this belief may be effective at increasing organic purchases.

There are several directions of interest for future research. Given the strong link between attitudes about the benefits of organic produce and consumption, it could be useful to explore whether organic consumption is also linked to attitudes associated with external benefits. Future research could also apply more qualitative methods to investigate why the effect of trust is so small on the purchase frequency of organic. In-depth interviews and means-end chain techniques might be helpful to understand why the perception of private benefits is such a strong driver of organic shopping compared with other types of beliefs about organic food and farming practices. Our results indicate that determinants differ depending on the product. Future studies might include more organic products, or add the conventional alternatives, in order to examine household substitution patterns.

\section{References}

Aertsens, J., Verbeke, W., Mondelaers, K., van Huylenbroeck, G., 2009. Personal determinants of organic food consumption: a review. British Food Journal 111 (10), 1140 - 1167.

Agarwal, J. and Malhotra, N.K., 2005. "An integrated model of attitude and affect: theoretical foundation and an empirical investigation", Journal of Business Research 58(4), 483-93. 
Ajzen, I., 1991. The theory of planned behavior. Organizational Behavior and Human Decision Processes 50 (2), 179-211.

Ajzen, I. and Fishbein, M. (2008), "Scaling and testing multiplicative combinations in the expectancy-value model of attitudes", Journal of Applied Social Psychology 38(9), 22222247.

Allen, M. W., Gupta, R., Monnier, A., 2008. The interactive effect of cultural symbols and human values on taste evaluation. Journal of Consumer Research 35 (2), 294-398.

Asp, E. H., 1999. Factors affecting food decisions made by individual consumers. Food Policy $24(2-3), 287294$.

Barber, B., 1983. The logic and limits of trust. Rutgers University Press.

Becker, N., Tavor, T., Friedler, L., Bar (Kutiel), P., 2016. Consumers' preferences toward organic tomatoes: A combined tow-phase revelead-stated approach. Journal of International Food \& Agribusiness Marketing 28(1), 1-17.

Chang, L., \& Krosnick, J. A. (2009). National surveys via RDD telephone interviewing versus the internet: Comparing sample representativeness and response quality. Public Opinion Quarterly, 73(4), 641-678.

Corrigan, J. R., Depositario, D. P. T., Nayga, R. M., Wu, X., Laude, T. P., 2009. Comparing open-ended choice experiments and experimental auctions: An application to golden rice. American Journal of Agricultural Economics 91 (3), 837-853.

Daniells, S., January 2014. U.S. organic food market to grow 14\% from 2013-18. http://www.foodnavigator-usa.com/Markets/US-organic-food-market-to-grow-14-from2013-18, accessed on 6 March 2016.

de Boer, J., Boersema, J. J., Aiking, H., 2009. Consumers' motivational associations favouring free-range meat or less meat. Ecological Economics 68 (3), 850-860.

de Jonge, J., van Trijp, H., Goddard, E., Frewer, L., 2008a. Consumer confidence in the safety of food in Canada and the Netherlands: The validation of a generic framework. Food Quality and Preference 19 (5), 439-451.

de Jonge, J., van Trijp, J., van der Lans, I., Renes, R., Frewer, L., 2008b. How trust in institutions and organizations builds general consumer confidence in the safety of food: A decomposition of effects. Appetite 51, 311-317. 
Dimitri, C., Greene, C., September 2002. Recent growth patterns in the U.S. organic foods market. Economic Information Bulletin 777, United States Department of Agriculture Economic Research Service.

Ding, Y., Veeman, M. M., Adamowicz, W. L., 2012. The impact of generalized trust and trust in the food system on choices of a functional GM food. Agribusiness 28 (1), 54-66.

Eden, S., Bear, C., Walker, G., 2008a. The skeptical consumer? Exploring views about food assurance. Food Policy 33 (6), 624-630.

Eden, S., Bear, C., Walker, G., 2008b. Understanding and (dis)trusting food assurance schemes: Consumer confidence and the 'knowledge fix'. Journal of Rural Studies 24, 1-14.

ERS, U., September 2013. U.S. certified organic farmland acreage, livestock numbers, and farm operations. http://ers.usda.gov/Data-products/organic-production.aspx, accessed on 4 March 2015.

Forman, J., Silverstein, J., 2012. Organic foods: Health and environmental advantages and disadvantages. Pediatrics.

Gil, J., Gracia, A., Sanchez, M., 2000. Market segmentation and willingness to pay for organic products in Spain. International Food and Agribusiness Management Review 3 (2), 207226.

Glaeser, E. L., Scheinkman, D. I. L. J. A., Soutter, C. L., 2000. Measuring trust. The Quarterly Journal of Economics 115 (3), 811-846.

Gracia, A., de Magistris, T., 2008. The demand for organic foods in the South of Italy: A discrete choice model. Food Policy 33 (5), 386-396.

Grebitus, C., Menapace, L., Bruhn, M., 2011a. Consumers' use of seals of approval and origin information: evidence from the German pork market. Agribusiness 27 (4), 478-492.

Grebitus, C., Steiner, B., Veeman, M.M., 2015. On the role of human values and trust when food is labeled for environmental footprints: Insights from Germany. Food Policy, 52(April), 84-91.

Grebitus, C., Yue, C., Bruhn, M., Jensen, H. H., 2011b. Perceived quality in organic and conventional pork markets in Germany. Food Economics 8 (4), 187-199.

Greene, W. H., Hensher, D. A., 2010. Modeling Ordered Choices: A Primer. Cambridge University Press, Ch. Bivariate and multivariate ordered choice models, pp. 268-289. 
Hair, J.F. (2009). Multivariate data analysis: A global perspective (7th ed.).Upper Saddle River, NJ: Prentice Hall.

Honkanen, P., Verplanken, B., \& Olsen, S.O., 2006. Ethical values and motives driving organic food choice. Journal of Consumer Behavior, 5, 420-430.

Howard, P. H., 2009. Consolidation in the North American organic food processing sector, 1997 to 2007. International Journal of Sociology of Agriculture and Food 16 (1), 13-30.

Hughner, R. S., McDonagh, P., Prothero, A., Shultz, C. J., Stanton, J., 2007. Who are organic food consumers? A compilation and review of why people purchase organic food. Journal of Consumer Behaviour 6 (2-3), 94-110.

Johnson, B., Slovic, P., 1994. "Improving" risk communication and risk management: Legislated solutions or legislated disasters? Risk Analysis 14 (6), 905-906.

Kaiser, H. F., 1974. An index of factorial simplicity. Psychometrika 39 (1), 31-36.

Lobb, A., Mazzocchi, M., Traill, W., 2007. Modelling risk perception and trust in food safety information within the theory of planned behaviour. Food Quality and Preference 18 (2), 384- 395.

Magnusson, M. K., Arvola, A., Hursti, U.-K. K., Lars Åberg, P.-O. S., 2003. Choice of organic foods is related to perceived consequences for human health and to environmentally friendly behaviour. Appetite 40 (2), 109-117.

Mansbridge, J., 1999. Democracy and Trust. Cambridge University Press, Ch. Altruistic Trust, pp.290-309.

McCluskey, J. J., 2000. A game theoretic approach to organic foods: An analysis of asymmetric information and policy. Agricultural and Resource Economics Review 29 (1), 1-9.

McFadden, D., 1974. Frontiers in Econometrics. Academic Press, New York, Ch. Conditional logit analysis of qualitative choice behavior, pp. 105-142.

Mosier, S.L., Thilman, D., 2016. Diffusion of food policy in the U.S.: The case of organic certification. Food Policy 61, 80-91.

Nandi, R., Bokelmann, W., Gowdru, N.V., Dias, G., 2016. Consumer motives and purchase preferences for organic food products: Emprirical evidence from a consumer survey in Bangalore, South India. Journal of International Food \& Agribusiness Marketing 28 (1), 74-99. 
Nie, C., Zepeda, L., 2011. Lifestyle segmentation of us food shoppers to examine organic and local food consumption. Appetite 57, 28-37.

Osteen, C., Gottlieb, J., (eds.), U. V., August 2012. Agricultural resources and environmental indicators, 2012 edition. Economic Information Bulletin 98, United States Department of Agriculture Economic Research Service.

Roosen, J., Bieberstein, A., Blanchemanche, S., Goddard, E., Marette, S., Vandermoer, F., 2015. Trust and willingness to pay for nanotechnology food. Food Policy (fortcoming).

Rousseau, S., Vranken, L., 2013. Green market expansion by reducing information asymmetries: Evidence for labeled organic food products. Food Policy 40, 31-43.

Saba, A. and Messina, F., 2003. "Attitudes towards organic foods and risk/benefit perception associated with pesticides", Food Quality and Preference 14, 637-45.

Schösler, H., de Boer, J., Boersema, J. J., 2013. The organic food philosophy. a qualitative exploration of the practices, values, and beliefs of Dutch organic consumers within a cultural-historical frame. Journal of Agricultural and Environmental Ethics 26 (2), 439460.

Schumacher, I., 2010. Ecolabeling, consumers' preferences and taxation. Ecological Economics 69 (11), 2202-2212.

Smith, T. A., Huang, C. L., Lin, B.-H., 2009. Does price or income affect organic choice? Analysis of U.S. fresh produce users. Journal of Agricultural and Applied Economics 41 (3), 731-744.

Smith-Spangler, C., Brandeau, M. L., Hunter, G. E., Bavinger, J. C., Pearson, M., Eschbach, P. J., Sundaram, V., Liu, H., Schirmer, P., Stave, C., Olkin, I., Bravata, D. M., September 2012. Are Organic Foods Safer or Healthier Than Conventional Alternatives?: A Systematic Review. Annals of Internal Medicine 157 (5), 348-366.

Steiner, B. E., Yag, J., 2010. How do U.S. and Canadian consumers value credence attributes associated with beef labels after the North American BSE crisis of 2003? International Journal of Consumer Studies 34 (4), 449-463.

Thøgersen, J., 2002. "Direct experience and the strength of the personal norm-behavior relationship", Psychology \& Marketing 19 (10), 881-93.

Thompson, G. D., 1998. Consumer demand for organic foods: What we know and what we need to know. American Journal of Agricultural Economics 80 (5), 1113-1118. 
USDA AMS, 2015. Introduction to Organic Practices. United States Department of Agriculture Agricultural Marketing Service, September 2015. https://www.ams.usda.gov/publications/content/introduction-organic-practices accessed on March 6, 2016.

USDA ERS, 2015. Agricultural Act of 2014: Highlights and Implications. http://www.ers.usda.gov/agricultural-act-of-2014-highlights-and-implications/organicagriculture.aspx accessed on March 6, 2016.

USDA ERS, 2016. Organic Agriculture Overview. http://www.ers.usda.gov/topics/naturalresources-environment/organic-agriculture.aspx accessed on March 6, 2016.

Uslaner, E. M., 2002. The Moral Foundations of Trust. Cambridge University Press.

Uslaner, E. M., 2008. The handbook of social capital. Oxford University Press, Ch. Trust as a moral value, pp. 101-121.

Veldstra, M.D., Alexander, C.E., Marshall, M.I., 2014. To certify or not to certify? Separating the organic production and certification decisions. Food Policy 49, 2014.

Verhoef, P. C., 2005. Explaining purchases of organic meat by Dutch consumers. European Review of Agricultural Economics 32 (2), 245-267.

Vukaspvič, T., 2016. Consumers' perceptions and behaviors regarding organic fruits and vegetables: Marketing trends for organic food in the twenty-first century. Journal of International Food \& Agribusiness Marketing 28(1), 59-73.

Walter, S., Schmidt, M., 2008. Carbon footprints und carbon label: Eine echte Hilfe bei der Kaufentscheidung? UmweltWirtschaftsForum 16 (3), 175-181.

Whitmarsh, L., O’Neill, S., 2010. Green identity, green living? The role of pro-environmental self-identity in determining consistency across diverse pro-environmental behaviors. Journal of Environmental Psychology, 30, 305-314.

Yeager, D. S., Krosnick, J. A., Chang, L. C., Javitz, H. S., Levendusky, M. S., Simpser, A., et al. (2010). Comparing the accuracy of RDD telephone surveys and internet surveys conducted with probability and non-probability samples. Public Opinion Quarterly, 75(4), 709-747.

Yamagishi, T., Yamagishi, M., 1994. Trust and commitment in the United States and Japan. Motivation and Emotion 18 (2), 129-166. 
Yiridoe, E. K., Bonti-Ankomah, S., Martin, R.C., 2005. Comparison of consumer perceptions and preference toward organic versus conventionally produced foods: A review and update of the literature. Renewable Agriculture and Food Systems 20(4), 193-205.

Yue, C., Grebitus, C., Bruhn, M., Jensen, H. H., 2010. Marketing organic and conventional potatoes in Germany. The Journal of International Food and Agribusiness Marketing 22 $(1 \& 2), 164-178$.

Zanoli, R., Naspetti, S., 2002. Consumer motivations in the purchase of organic food: A meansend approach. British Food Journal 104 (8), 643-653. 
Table 1: Mean, standard deviation (in parenthesis) and descriptions of explanatory variables for our sample $(\mathrm{N}=176)$ and the U.S. population.

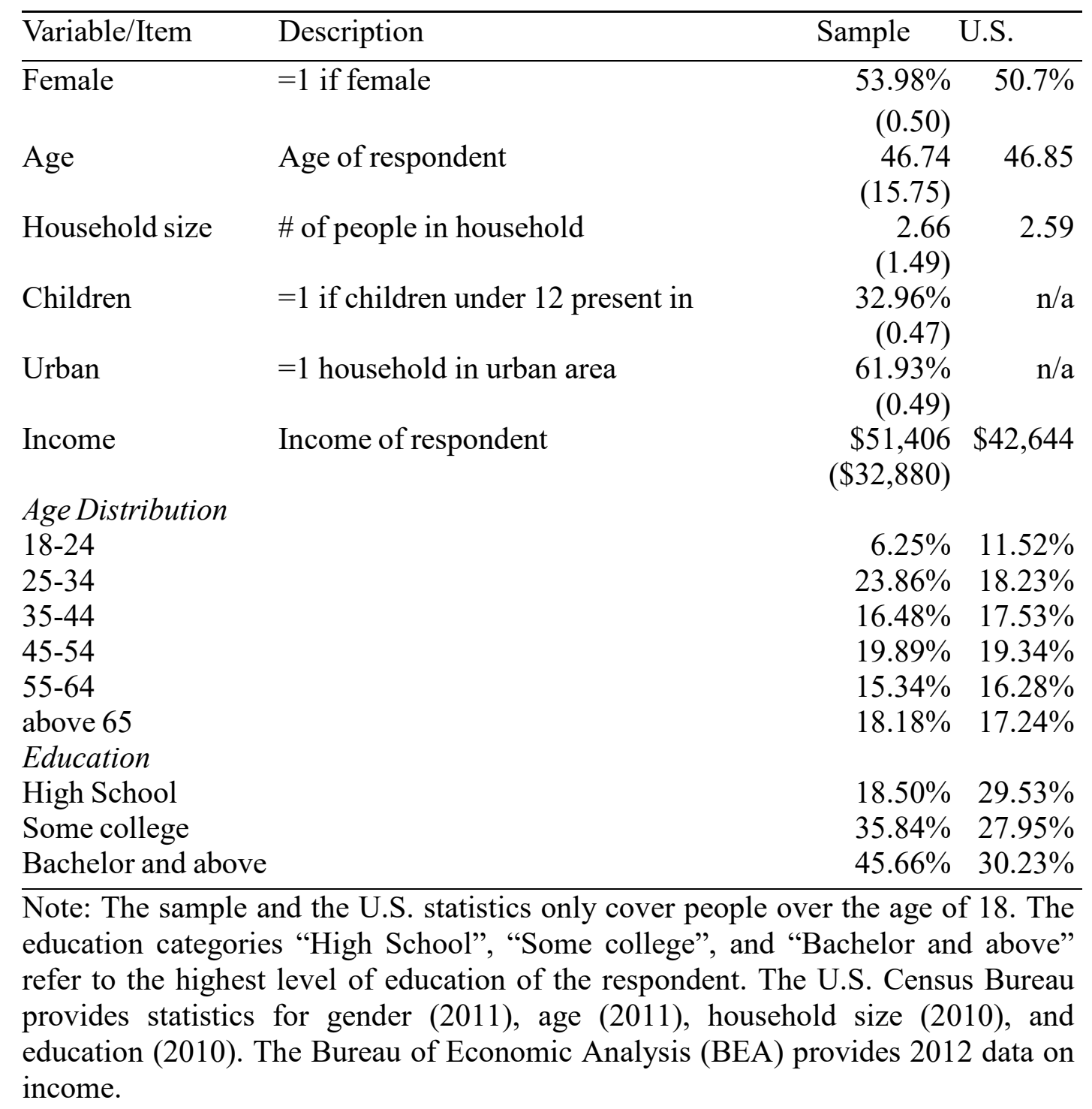


Table 2: Purchase frequency of organic strawberries and tomatoes.

\begin{tabular}{lccccccc}
\hline & \multicolumn{7}{c}{ Organic Tomatoes } \\
\cline { 2 - 8 } $\begin{array}{l}\text { Organic } \\
\text { Strawberries }\end{array}$ & Never & Rarely & $\begin{array}{c}\text { Once per } \\
\text { month }\end{array}$ & $\begin{array}{c}\text { Every two } \\
\text { weeks }\end{array}$ & $\begin{array}{c}1-2 \text { times } \\
\text { a week }\end{array}$ & $\begin{array}{c}\text { Almost } \\
\text { Daily }\end{array}$ & Total \\
\hline Never & 60 & 7 & 3 & 0 & 0 & 1 & 71 \\
Rarely & 2 & 26 & 9 & 3 & 3 & 0 & 43 \\
Once per month & 2 & 2 & 10 & 3 & 3 & 2 & 22 \\
Every two weeks & 0 & 0 & 2 & 7 & 4 & 3 & 16 \\
1-2 times a week & 1 & 1 & 0 & 3 & 5 & 2 & 12 \\
Almost Daily & 0 & 0 & 0 & 0 & 3 & 9 & 12 \\
\hline Total & 65 & 36 & 24 & 16 & 18 & 17 & 176 \\
\hline
\end{tabular}

Note: The polychoric correlation coefficient between organic strawberries and tomatoes is $\rho=0.88$ 
Table 3: Factor analysis on trust in sources of information about organic food.

\begin{tabular}{lrrrrrr}
\hline Items & Mean & S.D. & F1 & F2 & F3 & F4 \\
\hline Factor 1: Media & & & & & & \\
Newspapers, magazine, books & 2.90 & 0.88 & $\mathbf{0 . 8 6}$ & 0.23 & 0.08 & 0.15 \\
Internet & 2.76 & 0.95 & $\mathbf{0 . 8 7}$ & 0.14 & 0.02 & 0.06 \\
TV, radio & 2.59 & 0.90 & $\mathbf{0 . 7 8}$ & -0.04 & 0.18 & 0.31 \\
Factor 2: Third Party & & & & & & \\
University researcher & 3.69 & 0.86 & 0.00 & $\mathbf{0 . 8 3}$ & 0.20 & 0.21 \\
Non-profit organization & 3.54 & 0.90 & 0.24 & $\mathbf{0 . 7 6}$ & 0.22 & 0.09 \\
Third party certifier & 3.50 & 0.98 & 0.16 & $\mathbf{0 . 8 5}$ & -0.06 & -0.03 \\
Factor 3: Peers & & & & & & \\
Farmer groups & 3.70 & 0.82 & -0.01 & 0.10 & $\mathbf{0 . 7 9}$ & 0.17 \\
Health professionals (e.g., doctors) & 3.65 & 0.89 & 0.07 & 0.32 & $\mathbf{0 . 5 7}$ & 0.36 \\
Family, Friends, Colleagues & 3.52 & 0.88 & 0.30 & 0.12 & $\mathbf{0 . 7 3}$ & -0.12 \\
Factor 4: Industry/Government & & & & & & \\
Retailer & 3.04 & 0.82 & 0.39 & 0.09 & 0.37 & $\mathbf{0 . 5 1}$ \\
Government & 2.93 & 1.04 & 0.17 & 0.28 & -0.18 & $\mathbf{0 . 7 7}$ \\
Manufacturing company & 2.89 & 0.98 & 0.21 & -0.04 & 0.31 & $\mathbf{0 . 7 9}$ \\
\hline Eigenvalues & & & 4.28 & 1.68 & 1.40 & 1.10 \\
\hline
\end{tabular}

Note: Trust is measured on a 5-point Likert scale ranging from 1 ("not at all trustworthy") to 5 ("extremely trustworthy"). This table includes the variables and factor loadings used to create factor scores. The numbers in bold represent the maximum factor loading values, which are used in the assignment of groups. $\mathrm{KMO}=0.76$ and Cronbach's alpha $=0.83$. 
Table 4: Factor analysis on private benefits of organic food.

\begin{tabular}{|c|c|c|c|}
\hline Items & Mean & S.D. & F1 \\
\hline \multicolumn{4}{|l|}{ Factor 1: Private Benefits } \\
\hline Organically grown produce is safer to eat. & 3.58 & 0.97 & \\
\hline Organic produce is healthier than non-organic & 3.49 & 1.05 & 0.84 \\
\hline Organic produce tastes better. & 3.34 & 0.94 & 0.82 \\
\hline Organic produce is more nutritious. & 3.24 & 1.05 & 0.91 \\
\hline Eigenvalue & & & 2.92 \\
\hline
\end{tabular}

Note: Attitude is measured on a 5-point Likert scale ranging from 1 ("strongly disagree") to 5 ("strongly agree"). This table includes the variables and factor loadings used to create factor scores. The numbers in bold represent the maximum factor loading values used in the labeling of groups. $\mathrm{KMO}=0.77$ and Cronbach's alpha $=0.88$. 
Table 5: Factor analysis on organic farming practices.

\begin{tabular}{|c|c|c|c|c|}
\hline Items & Mean & S.D. & F1 & $\mathrm{F} 2$ \\
\hline \multicolumn{5}{|l|}{ Factor 1: Organic Practices } \\
\hline Organic produce has significantly less pesticide residuals. & 4.10 & 0.78 & 0.91 & 0.07 \\
\hline Organic produce is grown with little or no manufactured pesticides. & 4.01 & 0.85 & 0.91 & 0.01 \\
\hline $\begin{array}{l}\text { Organic produce is grown with little or no manufactured fertilizer. } \\
\text { Factor 2: Organic Image }\end{array}$ & 3.78 & 0.84 & $\mathbf{0 . 8 3}$ & 0.21 \\
\hline Organic produce is only grown on small family-owned farms. & 2.67 & 1.06 & -0.06 & 0.87 \\
\hline $\begin{array}{l}\text { Organic produce is less likely to carry disease-causing micro- } \\
\text { organisms (bacteria and fungi). }\end{array}$ & 3.27 & 1.02 & 0.37 & 0.68 \\
\hline $\begin{array}{l}\text { Organic produce is more expensive because it costs more to } \\
\text { produce. }\end{array}$ & 3.60 & 1.02 & 0.41 & 0.43 \\
\hline Eigenvalue & & & 2.91 & 1.19 \\
\hline
\end{tabular}

Note: Attitude is measured on a 5-point Likert scale ranging from 1 ("strongly disagree") to 5 ("strongly agree"). This table includes the variables and factor loadings used to create factor scores. The numbers in bold represent the maximum factor loading values used in the labeling of groups. $\mathrm{KMO}=0.75$ and Cronbach's alpha $=0.74$. 
Table 6: Parameter estimates and summary statistics of the bivariate ordered probit.

\begin{tabular}{|c|c|c|c|c|c|c|}
\hline & \multicolumn{3}{|c|}{ Organic Strawberries } & \multicolumn{3}{|c|}{ Organic Tomatoes } \\
\hline & Model 1 & Model 2 & Model 3 & Model 1 & Model 2 & Model 3 \\
\hline \multirow[t]{2}{*}{ Female } & -0.245 & -0.281 & -0.287 & -0.225 & -0.249 & -0.260 \\
\hline & $(0.179)$ & $(0.181)$ & $(0.182)$ & $(0.178)$ & $(0.180)$ & $(0.181)$ \\
\hline Age & $\begin{array}{c}-0.017 * * * \\
(0.006)\end{array}$ & $\begin{array}{c}-0.014 * * \\
(0.006)\end{array}$ & $\begin{array}{c}-0.016 * * \\
(0.007)\end{array}$ & $\begin{array}{c}-0.016 * * * \\
(0.006)\end{array}$ & $\begin{array}{c}-0.011 * \\
(0.006)\end{array}$ & $\begin{array}{c}-0.015 * * \\
(0.007)\end{array}$ \\
\hline \multirow[t]{2}{*}{ Household size } & -0.002 & 0.015 & 0.007 & 0.019 & 0.028 & 0.014 \\
\hline & $(0.079)$ & $(0.079)$ & $(0.079)$ & $(0.079)$ & $(0.078)$ & $(0.079)$ \\
\hline \multirow[t]{2}{*}{ Children } & 0.026 & -0.014 & -0.007 & -0.188 & -0.201 & -0.190 \\
\hline & $(0.244)$ & $(0.245)$ & $(0.246)$ & $(0.246)$ & $(0.245)$ & $(0.246)$ \\
\hline \multirow[t]{2}{*}{ Urban } & 0.298 & 0.24 & 0.219 & 0.217 & 0.216 & 0.18 \\
\hline & $(0.182)$ & $(0.184)$ & $(0.185)$ & $(0.180)$ & $(0.182)$ & $(0.183)$ \\
\hline \multirow[t]{2}{*}{ Income } & $0.055 *$ & 0.045 & $0.050 *$ & $0.083 * * *$ & $0.069 * *$ & $0.078 * * *$ \\
\hline & $(0.029)$ & $(0.029)$ & $(0.030)$ & $(0.029)$ & $(0.029)$ & $(0.030)$ \\
\hline \multirow[t]{2}{*}{ College } & 0.051 & 0.034 & 0.005 & -0.115 & -0.107 & -0.155 \\
\hline & $(0.189)$ & $(0.190)$ & $(0.191)$ & $(0.188)$ & $(0.189)$ & $(0.190)$ \\
\hline \multirow[t]{2}{*}{ Organic Practices } & -0.056 & -0.060 & -0.066 & -0.013 & -0.046 & -0.053 \\
\hline & $(0.107)$ & $(0.118)$ & $(0.118)$ & $(0.106)$ & $(0.117)$ & $(0.117)$ \\
\hline \multirow{2}{*}{ Organic Image } & 0.078 & 0 & 0.001 & 0.146 & 0.104 & 0.112 \\
\hline & $(0.096)$ & $(0.105)$ & $(0.105)$ & $(0.096)$ & $(0.104)$ & $(0.104)$ \\
\hline Private Benefits & $\begin{array}{c}0.317 * * * \\
(0.118)\end{array}$ & $\begin{array}{c}0.336 * * * \\
(0.120)\end{array}$ & $\begin{array}{c}0.352 * * * \\
(0.120)\end{array}$ & $\begin{array}{c}0.377 * * * \\
(0.118)\end{array}$ & $\begin{array}{c}0.363 * * * \\
(0.118)\end{array}$ & $\begin{array}{c}0.391 * * * \\
(0.119)\end{array}$ \\
\hline \multirow[t]{2}{*}{ Media } & & $0.210 * *$ & $0.194 * *$ & & 0.086 & 0.064 \\
\hline & & $(0.094)$ & $(0.094)$ & & $(0.093)$ & $(0.094)$ \\
\hline \multirow[t]{2}{*}{$3^{\text {rd }}$ Party } & & 0.074 & 0.043 & & 0.127 & 0.078 \\
\hline & & $(0.095)$ & $(0.098)$ & & $(0.095)$ & $(0.098)$ \\
\hline \multirow[t]{2}{*}{ Peers } & & -0.100 & -0.110 & & 0.023 & 0.006 \\
\hline & & $(0.092)$ & $(0.093)$ & & $(0.092)$ & $(0.092)$ \\
\hline \multirow[t]{2}{*}{ Ind/Gov } & & 0.09 & 0.081 & & 0.141 & 0.129 \\
\hline & & $(0.089)$ & $(0.089)$ & & $(0.088)$ & $(0.089)$ \\
\hline \multirow[t]{2}{*}{ General Trust } & 0.297 & & 0.255 & $0.477 * *$ & & $0.418 * *$ \\
\hline & $(0.188)$ & & $(0.196)$ & $(0.187)$ & & $(0.194)$ \\
\hline \multirow{3}{*}{$\rho 12$} & Model 1 & Model 2 & Model 3 & & & \\
\hline & $0.861 * * *$ & $0.874 * * *$ & $0.873 * * *$ & & & \\
\hline & $(0.027)$ & $(0.025)$ & $(0.025)$ & & & \\
\hline $\mathrm{N}$ obs & 176 & 176 & 176 & & & \\
\hline Log likelihood & -437.708 & -432.425 & -429.836 & & & \\
\hline
\end{tabular}

Note: * Significant at $10 \%$ level. ${ }^{* *}$ Significant at $5 \%$ level. $* * *$ Significant at $1 \%$ level. Standard errors in parentheses. 
Table 7: Parameter estimates of thresholds for the bivariate ordered probit model.

\begin{tabular}{ccccccc}
\cline { 2 - 7 } \multicolumn{2}{c}{ Organic Strawberries } & \multicolumn{3}{c}{ Organic Tomatoes } \\
\hline & Model 1 & Model 2 & Model 3 & Model 1 & Model 2 & Model 3 \\
\hline$\mu 1, \mathrm{k}$ & -0.611 & -0.645 & -0.680 & -0.598 & -0.602 & -0.672 \\
& $(0.426)$ & $(0.432)$ & $(0.434)$ & $(0.423)$ & $(0.427)$ & $(0.429)$ \\
$\mu 2, \mathrm{k}$ & 0.080 & 0.048 & 0.020 & 0.028 & 0.028 & -0.033 \\
& $(0.422)$ & $(0.427)$ & $(0.429)$ & $(0.422)$ & $(0.427)$ & $(0.429)$ \\
$\mu 3, \mathrm{k}$ & 0.512 & 0.484 & 0.459 & 0.484 & 0.487 & 0.436 \\
& $(0.419)$ & $(0.423)$ & $(0.425)$ & $(0.420)$ & $(0.425)$ & $(0.426)$ \\
$\mu 4, \mathrm{k}$ & $0.885^{* *}$ & $0.858^{* *}$ & $0.837^{* *}$ & $0.824^{* *}$ & $0.819^{*}$ & $0.773^{*}$ \\
& $(0.42)$ & $(0.426)$ & $(0.427)$ & $(0.419)$ & $(0.423)$ & $(0.425)$ \\
$\mu 5, \mathrm{k}$ & $1.324^{* * *}$ & $1.328^{* * *}$ & $1.304^{* * *}$ & $1.283^{* * *}$ & $1.264^{* * *}$ & $1.224^{* * *}$ \\
& $(0.426)$ & $(0.433)$ & $(0.433)$ & $(0.422)$ & $(0.426)$ & $(0.427)$ \\
\hline
\end{tabular}

Note: * Significant at 10\% level. ** Significant at 5\% level. *** Significant at $1 \%$ level. Standard errors in parentheses. 
Table 8: Predicted probabilities and marginal effects from the estimated bivariate ordered probit model evaluated at the sample average.

\begin{tabular}{|c|c|c|c|c|c|c|}
\hline & Never & Rarely & $\begin{array}{c}\text { Once per } \\
\text { month }\end{array}$ & $\begin{array}{c}\text { Every two } \\
\text { weeks }\end{array}$ & $\begin{array}{c}1-2 \text { times a } \\
\text { week }\end{array}$ & $\begin{array}{c}\text { Almost } \\
\text { daily }\end{array}$ \\
\hline \multicolumn{7}{|c|}{ Organic strawberries } \\
\hline Predicted prob. & 0.396 & 0.273 & 0.141 & 0.085 & 0.062 & 0.044 \\
\hline Variable & \multicolumn{6}{|c|}{ Marginal Effects } \\
\hline Female & 0.110 & -0.006 & -0.026 & -0.026 & -0.026 & -0.027 \\
\hline Age & $0.006 * *$ & 0.000 & $-0.001 * *$ & $-0.001 * *$ & $-0.001 * *$ & $-0.001 * *$ \\
\hline Household & -0.003 & 0.000 & 0.001 & 0.001 & 0.001 & 0.001 \\
\hline Children & 0.003 & 0.000 & -0.001 & -0.001 & -0.001 & -0.001 \\
\hline Urban & -0.085 & 0.006 & 0.020 & 0.020 & 0.020 & 0.019 \\
\hline Income & $-0.019 *$ & 0.001 & 0.005 & 0.005 & 0.005 & 0.005 \\
\hline College & -0.002 & 0.000 & 0.000 & 0.000 & 0.000 & 0.000 \\
\hline Organic Practices & 0.025 & -0.002 & -0.006 & -0.006 & -0.006 & -0.006 \\
\hline Organic Image & -0.001 & 0.000 & 0.000 & 0.000 & 0.000 & 0.000 \\
\hline Private Benefits & $-0.136 * * *$ & 0.008 & $0.032 * *$ & $0.032 * *$ & $0.032 * *$ & $0.032 * *$ \\
\hline Media & $-0.075 * *$ & 0.004 & $0.018 *$ & $0.017 *$ & $0.018 * *$ & $0.018 * *$ \\
\hline Peers & 0.042 & -0.003 & -0.010 & -0.010 & -0.010 & -0.010 \\
\hline Ind/Gov & -0.031 & 0.002 & 0.007 & 0.007 & 0.007 & 0.007 \\
\hline $3^{\text {rd }}$ Party & -0.016 & 0.001 & 0.004 & 0.004 & 0.004 & 0.004 \\
\hline General Trust & -0.097 & 0.003 & 0.022 & 0.023 & 0.024 & 0.025 \\
\hline \multicolumn{7}{|l|}{ Organic tomatoes } \\
\hline Predicted prob. & 0.347 & 0.25 & 0.165 & 0.091 & 0.08 & 0.066 \\
\hline Variable & \multicolumn{6}{|c|}{ Marginal Effects } \\
\hline Female & 0.0950 & 0.0050 & -0.020 & -0.021 & -0.026 & -0.034 \\
\hline Age & $0.005 * *$ & 0.0000 & $-0.001 * *$ & $-0.001 * *$ & $-0.001 * *$ & $-0.002 * *$ \\
\hline Household & -0.005 & 0.0000 & 0.0010 & 0.0010 & 0.0010 & 0.0020 \\
\hline Children & 0.0710 & 0.0020 & -0.016 & -0.015 & -0.019 & -0.023 \\
\hline Urban & -0.067 & -0.002 & 0.0140 & 0.0140 & 0.0180 & 0.0230 \\
\hline Income & $-0.029 * * *$ & -0.001 & $0.006 * *$ & $0.006^{* *}$ & $0.008 * *$ & $0.010 * *$ \\
\hline College & 0.0570 & 0.0020 & -0.012 & -0.012 & -0.015 & -0.020 \\
\hline Organic practices & 0.0200 & 0.0010 & -0.004 & -0.004 & -0.005 & -0.007 \\
\hline Organic Image & -0.041 & -0.002 & 0.0090 & 0.0090 & 0.0110 & 0.0140 \\
\hline Private Benefits & $-0.144 * * *$ & -0.007 & $0.030 * *$ & $0.031 * * *$ & $0.039 * * *$ & $0.050 * * *$ \\
\hline Media & -0.024 & -0.001 & 0.0050 & 0.0050 & 0.0060 & 0.0080 \\
\hline Peers & -0.002 & 0.0000 & 0.0000 & 0.0000 & 0.0010 & 0.0010 \\
\hline Ind/Gov & -0.048 & -0.002 & 0.0100 & 0.0100 & 0.0130 & 0.0170 \\
\hline $3^{\text {rd }}$ Party & -0.029 & -0.001 & 0.0060 & 0.0060 & 0.0080 & 0.0100 \\
\hline General Trust & $-0.148 * *$ & -0.015 & $0.028 * *$ & $0.032 * *$ & $0.043 * *$ & $0.061 * *$ \\
\hline
\end{tabular}

Note: * Significant at $10 \%$ level. ** Significant at $5 \%$ level. *** Significant at $1 \%$ level. 
Table 9: Descriptive statistics of consumer segments. $u$ and $l$ denote the maximum and minimum value for a variable.

\begin{tabular}{lccccc}
\hline Cluster & $\begin{array}{c}\text { General } \\
\text { Skeptics }\end{array}$ & $\begin{array}{c}\text { Organic } \\
\text { Skeptics }\end{array}$ & $\begin{array}{c}\text { Organic } \\
\text { Believers }\end{array}$ & Informed & Total \\
\hline N obs & 42 & 61 & 40 & 33 & 176 \\
\hline Variable & \multicolumn{5}{c}{ Mean } \\
Organic Practices & $-0.89^{l}$ & -0.25 & 0.41 & $1.09^{u}$ & 0.00 \\
Organic Image & 0.04 & -0.42 & $1.01^{u}$ & $-0.49^{l}$ & 0.00 \\
PrivateBenefits & -0.54 & $-0.60^{l}$ & $0.95^{u}$ & 0.64 & 0.00 \\
Media & 0.29 & $-0.47^{l}$ & $0.70^{u}$ & -0.35 & 0.00 \\
Peers & $-0.72^{l}$ & 0.09 & $0.48^{u}$ & 0.16 & 0.00 \\
Ind/Gov & $-0.88^{l}$ & $0.45^{u}$ & 0.33 & -0.12 & 0.00 \\
$3^{\text {rd } \text { Party }}$ & -0.26 & -0.05 & $-0.31^{l}$ & $0.80^{u}$ & 0.00 \\
General Trust & $0.23^{l}$ & 0.34 & 0.30 & $0.45^{u}$ & 0.32 \\
\hline
\end{tabular}


Table 10: Purchase patterns and socio-demographics of consumer segments. $u$ and $l$ denote the maximum and minimum value for a variable.

\begin{tabular}{lccccccc}
\hline Cluster & $\begin{array}{c}\text { General } \\
\text { Skeptics }\end{array}$ & $\begin{array}{c}\text { Organic } \\
\text { Skeptics }\end{array}$ & $\begin{array}{c}\text { Organic } \\
\text { Believers }\end{array}$ & Informed & & & \\
\hline N obs. & 42 & 61 & 40 & 33 & 176 & ANOVA & MANOVA \\
\hline Variable & & & & & & & \\
Organic strawberries & 1.17 & $1.00^{l}$ & $2.40^{u}$ & 1.12 & 1.38 & 0.00 & 0.00 \\
Organic tomatoes & 1.31 & $1.28^{l}$ & $2.73^{u}$ & 1.42 & 1.64 & 0.00 & \\
Age & 44.10 & 47.97 & $43.60^{l}$ & $51.66^{u}$ & 46.74 & 0.09 & \\
Household size & $2.43^{l}$ & 2.51 & $3.08^{u}$ & 2.73 & 2.66 & 0.18 & \\
Female & 0.55 & $0.44^{l}$ & 0.58 & $0.67^{u}$ & 0.54 & 0.20 & \\
Income (\$10k) & $4.41^{l}$ & $5.73^{u}$ & 5.02 & 5.25 & 5.16 & 0.25 & 0.02 \\
College & 0.46 & $0.49^{u}$ & 0.48 & $0.33^{l}$ & 0.45 & 0.48 & \\
Children & 0.33 & 0.26 & $0.50^{u}$ & $0.24^{l}$ & 0.33 & 0.05 & \\
Urban & $0.45^{l}$ & $0.69^{u}$ & 0.68 & 0.64 & 0.62 & 0.08 & \\
\hline
\end{tabular}

